\title{
REVIEW
}

\section{Translating Phytobiomes from Theory to Practice: Ecological and Evolutionary Considerations}

\author{
Christine V. Hawkes ${ }^{\dagger}$ and Elise W. Connor, Department of Integrative Biology, 1 University Station C0990, \\ University of Texas, Austin, TX 78712
}

Accepted for publication 2 June 2017.

\begin{tabular}{|c|c|}
\hline $\begin{array}{l}\text { The tremendous potential of the plant microbiome to improve } \\
\text { plant growth and production means that microbes are in the } \\
\text { process of becoming an everyday tool in agronomic practices. } \\
\text { However, historically field applications of microbes have had low } \\
\text { success. We propose that development and optimization of } \\
\text { microbiome treatments will benefit from the integration of } \\
\text { ecological and evolutionary niche theory into plant microbiome } \\
\text { studies. Thus, we review several niche-based processes that can } \\
\text { aid in the development and implementation of microbiome } \\
\text { treatments. Current predictive approaches include evolutionary } \\
\text { history, habitat origin, ecological traits, resource trade, and gene } \\
\text { signatures, none of which are mutually exclusive. A robust } \\
\text { predictive framework must further account for observed plasticity }\end{array}$ & $\begin{array}{l}\text { and context dependence in microbial function. Development of } \\
\text { microbiome treatments that will successfully establish in the field } \\
\text { can also benefit from a better understanding of niche-based } \\
\text { processes such as niche partitioning to limit competitive } \\
\text { interactions and maximize persistence, priority effects to allow } \\
\text { establishment before resident taxa, storage effects that take } \\
\text { advantage of temporal variation in niche availability, and local } \\
\text { adaptation to specific environments. Using endophytic fungi as } \\
\text { examples, we illustrate current knowledge and gaps in these } \\
\text { areas. Finally, we address existing limitations to the broad-scale } \\
\text { development of successful microbiome tools. } \\
\text { Additional keywords: agriculture, ecology. }\end{array}$ \\
\hline
\end{tabular}

The plant phytobiome goes beyond the plant to consider both its biotic interactions and environmental conditions. The plant microbiome is one component of the phytobiome that is being increasingly viewed as a source of new tools for managing plant growth and production. The expected utility of the plant microbiome is based on evidence that microbial populations and communities affect plant fitness by, for example, moderating plant responses to stress caused by heat, drought, limited resources, insects, and pathogens (Arnold et al. 2003; Castillo Lopez et al. 2014; Johnson et al. 2015; Rodriguez et al. 2010). Indeed, our understanding of the controllers of plant physiology and physiological plasticity are being modified by studies of the plant microbiome (Arnold and Engelbrecht 2007; Giauque and Hawkes 2013). Microbial treatments are particularly appealing as a way to overcome limitations of plant breeding, including observed trade-offs in crop yield and stress resistance (Tack et al. 2016) that are expected to restrict yield improvements to 7 to $15 \%$ under future climate scenarios (Challinor et al. 2014).

The use of microbiome tools in agriculture requires the development of native or engineered microbial populations or communities that can be inoculated on the plant (Farrar et al. 2014; Kumar et al.

${ }^{\dagger}$ Corresponding author: C. V. Hawkes; E-mail: chawkes@austin.utexas.edu

(C) 2017 The American Phytopathological Society
2016; Mueller and Sachs 2015; Rodriguez et al. 2004). However, many past efforts at microbial inoculations have been ineffective in the field, both in improving plant performance and in persisting over time, despite strong support from greenhouse studies (Van Veen et al. 1997). These failures are most likely caused by the use of microbes targeting specific benefits or functions, regardless of how those microbes may interact with complex microbial communities already residing in the plant. We postulate that to effectively exploit the enormous potential of the plant microbiome, plant-associated microbial communities must be considered in an ecological context.

In particular, we argue that most microbiome processes are nichebased, with the microbial niche defined as all of the ecological requirements and roles of an organism in the plant ecosystem (Table 1) (Chase and Leibold 2009). The fundamental niche of a species is reduced by interactions with other species to its actual or realized niche (Hutchinson 1957), which ultimately means that species cannot coexist if they occupy the exact same niche space due to competition (Gause 1934; Hutchinson 1957). Conversely, niche partitioning (Table 1) is expected to reduce competitive interactions, lead to variation in environmental tolerances, and allow for coexistence (Tilman 1999). From a niche-based perspective, predicting microbiome functioning as it relates to plant performance and developing robust treatments depends on our understanding of microbial interactions, community assembly processes, and environmental 
conditions. Most efforts to date have focused on single microbial taxa as inoculants, but these are likely to have lower success and be less persistent when faced with resident microbial communities.

We start by addressing niche-based ecological and evolutionary approaches for broad-level prediction of microbiome effects on plants. Specifically, we focus on factors potentially related to niche partitioning or overlap: evolutionary history (phylogeny), habitat, ecological traits, resources, and genes. In addition, we discuss how microbial plasticity and the environment can alter the outcome of plant-microbe interactions and intended benefits. We then examine how niche processes in the field can serve as both impediment or opportunity for the establishment and persistence of microbiome treatments. These include niche partitioning based on function, temporal variation in arrival (priority effects), environmental variation over time (storage effects), and environmental variation across habitats (local adaptation). For each ecological process, we further consider methods of study and application. Finally, we point out some of the barriers to implementing niche-based microbiome treatments,

TABLE 1

Definitions of ecological and evolutionary terms

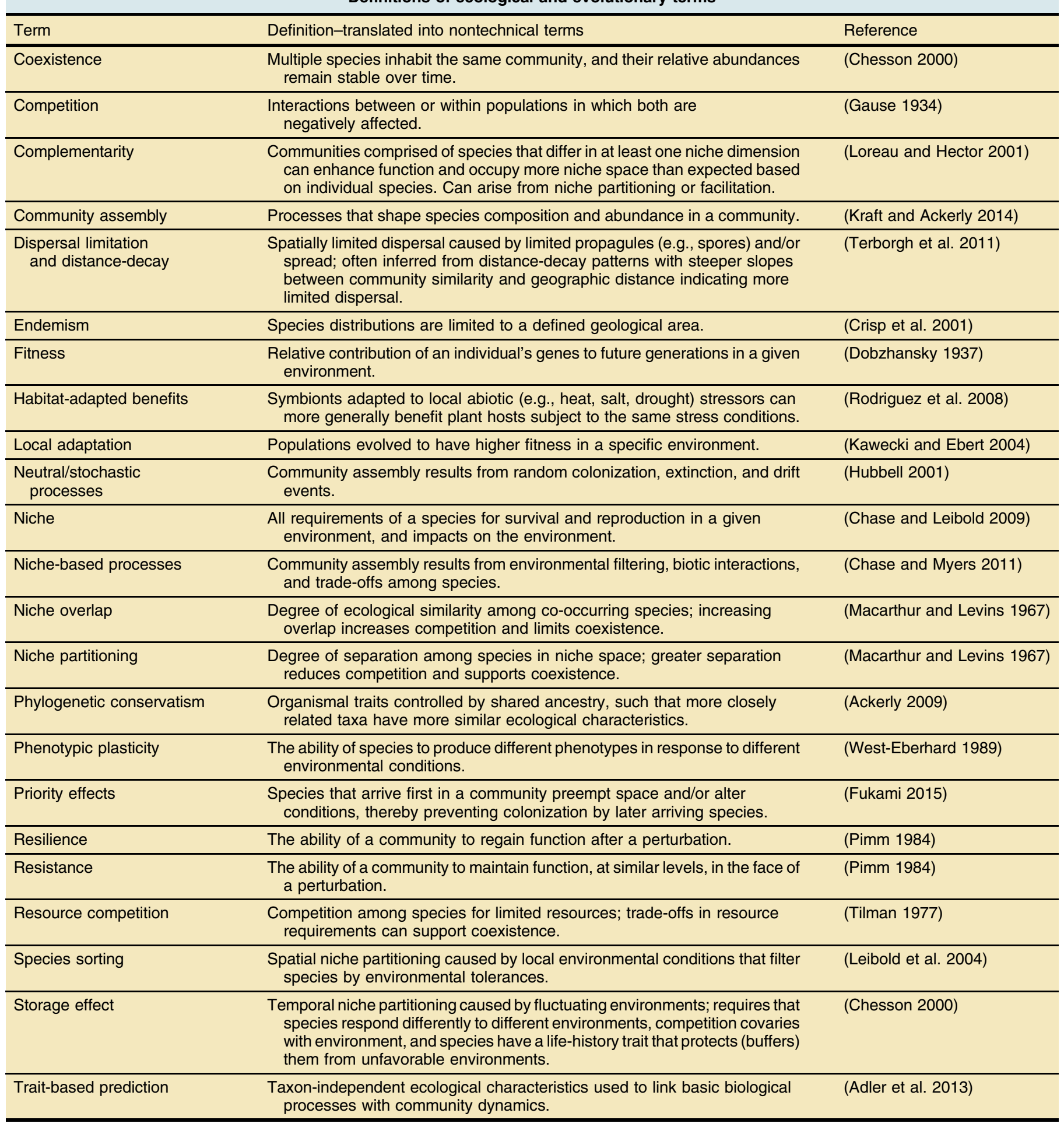


including the potential role for neutral processes, technological issues, and scaling of inoculum production.

In order to further delve into the role of these ecological concepts in microbiome applications, we focus on horizontally transmitted fungal endophytes in leaves and roots as examples. These fungi, including foliar endophytes, root endophytes, and arbuscular mycorrhizas, are a functionally important component of the plant microbiome known for mediating plant stress physiology, nutrient uptake, and resistance to insects and pathogens (Hamilton et al. 2012; Hartley et al. 2015; Newsham 2011; Oelmüller et al. 2009; Redman et al. 2002; Worchel et al. 2013). Because of these benefits, fungal endophytes are a common target and are already used for agronomic applications such as insecticides, whereas mycorrhizal fungi are common soil additives. There is also evidence that endophytic fungi are shared across related host plants (Giauque and Hawkes 2016; Higgins et al. 2014), enhancing their potential value for use in multiple crops. However, the ideas presented here also apply to the broader phytobiome, which essentially defines the full abiotic and biotic components of the realized plant niche.

\section{PREDICTING MICROBIOME EFFECTS ON PLANTS}

The ability to predict how individual microbial taxa and interactions among microbial taxa affect plant traits is key to the development of microbial populations and communities as plant management tools. Basing prediction on niche processes can help to optimize treatment development and application because niche theory uses species interactions to understand which taxa can coexist in the plant. For example, microbial populations can be targeted based on potential facilitative interactions with resident microbiota. Similarly, niche predictions can be used to develop stable treatment consortia where the probability of long-term coexistence is maximized. In addition, identifying general predictors of whether a microbial population or community is beneficial or detrimental for plant traits of interest, such as growth, drought tolerance, and pathogen resistance, will facilitate understanding the basic drivers of the symbiosis and advancing beyond unique special-case treatments. There are currently five putative predictors for fungal function: shared evolutionary history, habitat origin, ecological traits, resource-based interactions, and fungal genomics. Support exists for each framework, but no generalizations can be made at this time.

Evolutionary constraints on how symbionts function in plants would make for relatively simple predictions given associations based on phylogenetic relatedness in the microbiome. Specifically, if more closely related species are more functionally similar, then function in untested microbial taxa could be predicted from close relatives that have been studied (Martiny et al. 2015). We might also expect, for example, that if function is phylogenetically conserved (Table 1), then microbiome treatments comprised of phylogenetically related taxa would be more likely to compete. Arbuscular mycorrhizas show phylogenetic conservatism for root colonization, soil hyphal network size, and some host benefits (Maherali and Klironomos 2007; Powell et al. 2009), meaning that different genera have characteristic traits that may be important for how they interact with the plant, such as a predominance of hyphae inside versus outside the root. To date, however, no strong phylogenetic conservation has been observed for any traits of root or leaf endophytic fungi, possibly because of the evolutionary instability of many fungal lineages that have repeatedly shifted between endophytic and pathogenic lifestyles (Delaye et al. 2013). In addition, horizontal gene transfer in fungi occurs at the rate of 1.8 to $4.1 \%$ of genes per genome and can undermine phylogenetic patterns, particularly in the Pezizomycotina that encompasses many genera of fungal endophytes (Wisecaver et al. 2014). Using phylogenetic information to predict microbial function in symbiosis may be more suited to obligate symbionts compared with facultative symbionts. Nevertheless, there have been few studies of endophytes in this context and a wide variety of in planta functional data are needed to better assess the potential for phylogenetic relatedness to play a role in predicting the outcomes of symbiosis.

Habitat origin effects are predicated on the idea that microbial adaptation (Table 1) to the local abiotic environment generates consistent function in symbionts, whereby microbial benefits to the plant are likely to be conferred across multiple hosts in matched environmental conditions. Such habitat origin effects have been observed in which fungi isolated from native plants in geothermal or salt-stressed habitats improve plant tolerance of related stressors in crop plants (Redman et al. 2011; Rodriguez et al. 2008). However, habitatadapted benefits (Table 1) were not found for foliar endophytes across a less severe stress gradient (Giauque and Hawkes 2013). It is possible that geographic isolation (which limits gene flow) and the strength of selection may play a role, where fungi that are more isolated in extreme environmental conditions are more likely to develop habitat-adapted benefits. Alternatively, fungal species can sort (Table 1) by environmental preference or tolerance and those may be decoupled from their function in symbiosis (Giauque and Hawkes 2013, 2016). Because most endophytes are not obligate symbionts and have life stages both inside and outside of plant hosts, their selective environments are complex. Determining which habitat characteristics (e.g., degree of stress and isolation) transcend fungal life stages and select for plant-beneficial traits is a necessary step in identifying indicators of habitat-adaptation.

Ecological traits can be used instead of individual microbial species identities when those traits represent specific functions or outcomes in symbiosis. Traits have been proposed to explain several fungal community processes including assembly, interactions, and distributions (e.g., Saunders et al. 2010), although few have been explicitly tested. Most microbial trait frameworks (Table 1) invoke individual traits and trade-offs from macroorganismal ecology, such as competitor-stress tolerator-ruderal theory (Chagnon et al. 2013) and related dominance-tolerance models (Crowther et al. 2014). In these theories, trade-offs are expected based on resource investment in different ecological strategies that affect species abundance, such that good competitors can dominate productive, stable ecosystems but have low tolerance for stress and poor dispersal capacity. For instance, competitive dominant fungal taxa may become abundant because they can obtain more carbon from plants, which can be beneficial if the fungus provides some service to the plant (e.g., pathogen protection) when carbon is available in excess (e.g., photosynthesis is not constrained by shade or drought). However, under stressful conditions a fungus with traits for competitive dominance may harm the plant by using limited carbon and preventing its allocation to other plant needs. Thus, we might expect a trade-off between competitive dominant strategies for fungi in productive habitats versus stress tolerant fungi in more stressful abiotic or biotic sites, which could prove predictive of plant benefits from those fungi in treatment consortia.

Given that microbes occur in complex communities, another possibility is that traits should be considered at the community level based on metagenomic or metatranscriptomic profiles (Fierer et al. 2014; Jiang et al. 2016), meaning that functional genes or gene expression summed across taxa might better represent the overall community function compared with individual microbial species characteristics. For example, metagenomic analysis of the endophyte community in rice roots revealed genes for detoxification of reactive oxygen species and most components of the nitrogen cycle, suggesting a role in plant stress tolerance and nutrient access (Sessitsch et al. 2011). Nevertheless, the presence of genes and information on their expression provides only an indicator of potential function and as such are traits that must still be connected to actual function in order to 
make them useful for prediction. Although a benefit of trait-based approaches is that they require no prior assumptions about mechanism, functional response traits at either individual or community levels can result from complex underlying mechanisms including multiple metabolic pathways. Thus, a perpetual challenge with trait-based approaches is translating the conceptual framework into a quantitative operational approach; Adler et al. (2013) suggest explicitly linking traits to coexistence mechanisms to facilitate trait-based prediction.

Resource-based models are primarily applied to arbuscular mycorrhizal fungi. These models assume that the relative amounts of available plant carbon, soil nitrogen, and soil phosphorus, and the trade balance between plant and fungus, control how mycorrhizal fungi function across the continuum from parasitism to mutualism (Johnson 2010). Experimental manipulations demonstrate that mycorrhizal fungi are more likely to be mutualists when phosphorus is limited and more likely to be commensals or parasites when nitrogen is limited (Johnson et al. 2015). Thus, soil nutrient status may predict the degree of benefit provided by plant-mycorrhizal interactions.

Similar resource-based models also may apply to horizontally transmitted root endophytes that play a role in nutrient uptake. In horizontally transmitted leaf endophytes, resource-based models likely need to consider carbon supply balanced against other nonresource fungal benefits; for example, we might contrast the idea that the degree of stress benefit provided by foliar endophytes is proportional to current or recent carbon availability with one that assumes that fungal composition shifts under stress toward more stressbeneficial fungi regardless of carbon. Many fungal endophytes can use host carbon substrates in vitro and produce a broad array of enzymes for carbon degradation (Carroll and Petrini 1983; Govinda Rajulu et al. 2011; Longoni et al. 2012); however, resource-based models have not been explicitly tested in root or foliar fungal endophytes. To begin applying resource-based models to endophytes, basic data on fungal-plant physiological interactions are needed, including rates of fungal sugar uptake, carbohydrate degradation from cell walls, nutrient exchange, and stress benefits, as well as how their balances shift under different resource and stress levels.

In addition to these ecological approaches to microbiome functional prediction, fungal genomics may prove useful for forecasting functional potential. The increasing number of fungal genomes and genomic tools can facilitate comparative genomic and transcriptomic analyses to identify genes of interest for target functions (Grigoriev et al. 2014; Wisecaver et al. 2014). Genes are being discovered that permit the symbiont lifestyle (pathogenic to mutualistic) and regulate physiological effects on the plant, synthesis of secondary metabolites, and so on (Soanes et al. 2008; Wang et al. 2015; Zouari et al. 2014). For example, comparative genomic and transcriptomic analysis of the endophytic fungus Pestalotiopsis fici found 1.3 to $4.0 \times$ more genes encoding for candidate pectinases and other carbohydrate-active enzymes and 1.2 to $74.0 \times$ more secondary metabolite gene clusters compared with 17 other fungi including pathogens, decomposers, mycorrhizas, and other endophytes (Wang et al. 2015). Genomics studies can generate hypotheses for how the fungal endophyte symbiosis operates, such as the potential for fungal use of pectin in living plant tissue. As more data accumulate, genomics can be used to predict the fungal niche, potential competitive or facilitative interactions among taxa, and effects on the plant host (Zelezniak et al. 2015).

None of these predictors are necessarily mutually exclusive, but their disparate development means that few studies have attempted to simultaneously assess their relative importance. For example, only two studies have addressed phylogeny, habitat, and traits in fungal endophytes. For 36 foliar endophytes grown with Panicum virgatum seedlings, traits related to fungal stress tolerance and resource use predicted plant responses only in drought-stressed conditions, and phylogeny only mattered when considering interactions with fungal traits and habitat origin (Giauque 2016). In contrast, for 128 root endophytes, phylogeny was the best predictor of fungal behavior on growth of Arabidopsis thaliana and Microthlaspi erraticum, whereas both phylogeny and traits predicted growth of Hordeum vulgare (Kia et al. 2016). Partitioning the contributions of multiple predictors is important for understanding the ecology and evolution of these systems.

Integration of multiple approaches may improve functional predictions for microbiome effects on the host plant. For example, phylogenetic constraints on fungal distributions might predict their habitat or resource associations and thereby indirectly predict specific functions related to host stress or nutrient benefits. Although a single robust predictor would be a boon for screening and application development, the few studies to date suggest that any predictive framework is likely to include multiple predictors at the intersection of phylogeny, historical habitat conditions, and ecological traits that will depend on both the target benefits and current environmental conditions.

\section{CONTEXT DEPENDENCE AND PLASTICITY}

Predicting microbiome function must also account for environmental change and microbial functional breadth. Most microbes are phenotypically plastic (Table 1) in their responses to abiotic and biotic conditions (Angelard et al. 2014; Scaduto and Bennett 2015), meaning that trait expression for a given microbial genotype depends on the environment. Endophytic fungi can shift both the direction (beneficial or detrimental) and magnitude of their effects on plants as the environment changes (Giauque and Hawkes 2013; Goh et al. 2013). For example, across 36 foliar endophyte taxa, correlations of plant traits in drought versus well-watered conditions ranged from $8 \%$ for transpiration efficiency to $76 \%$ for height growth rate (Giauque 2016). Similar shifts can be seen for some endophytic fungi across plant hosts or genotypes (Mandyam et al. 2012; Petrini et al. 1993; Sikes et al. 2009). Indeed, fungal endophytes are known to switch from commensal or mutualist to pathogenic lifestyles depending on conditions (Carroll 1988; Jumpponen 2001; Schulz and Boyle 2005), with only a few genes differentiating the two states (Delaye et al. 2013; Redman et al. 1999). Although plasticity has been repeatedly demonstrated for individual microbial strains, for treatment applications we must also begin considering how plasticity affects interactions among taxa and how microbiome treatments affect plant plasticity across environments.

Plasticity in plant microbiome applications can be a benefit if environmental dependence is understood and shifts in endophyte physiology still meet the overall target treatment goals. Endophytes or communities of endophytes that are sufficiently plastic to persist under different environmental conditions, such as periodic drought, might be selected for microbiome treatments based on net benefits to plant survival even if, for example, they shift from mutualistic under drought to slightly parasitic under well-watered conditions. In contrast, endophytes that transition to pathogenic lifestyles when the plant host is stressed clearly would be poor choices. As our understanding of plant microbiome plasticity grows, combinations of taxa ranging from high-plasticity generalists to low-plasticity specialists may be able to buffer treatments across multiple environmental conditions akin to a functional storage effect (see below).

Although most studies focus on fungal plasticity, the mycobiome also affects plant plasticity (Goh et al. 2013). For example, shoot biomass plasticity of plants inoculated with endophytes was $1.8 \times$ that of endophyte-free control plants when measured with a standardized plasticity index; however, this effect varied across 20 individual endophytes from 0.16 to $7.8 \times$ (Giauque and Hawkes 2013). The effects of endophytes on plant plasticity have the potential to be beneficial for the host by expanding environmental 
tolerances and increasing resilience in unpredictable environments (Nicotra et al. 2010). Nevertheless, we understand very little about the relationship between fungal endophytes and plant plasticity. To exploit this aspect of endophytes in microbiome treatments, baseline studies are needed to establish general patterns of which plant traits are affected, whether fungi from different regions or with different phylogenetic histories have different impacts on plant plasticity, and under what conditions plasticity is induced by the fungi.

\section{ESTABLISHMENT AND MAINTENANCE OF TREATMENTS}

Implementing desired microbiome treatments in the field requires target microbial taxa to establish and persist when and where needed. Based on niche theory, we expect deterministic processes to dominate when both abiotic and biotic filters are strong: environmental filters such as temperature and precipitation will screen out taxa that cannot survive under local conditions, while interactions with the host plant and other components of the microbiome act as biotic filters (Chase and Myers 2011). Furthermore, niche-based competition and facilitation among microbial taxa can lead to unexpected functional effects (Connor et al. 2017; Jonkers et al. 2012). Niche partitioning can thus serve as a foundation for the development of microbial treatments designed to leverage community assembly processes. Here we address the role of niche partitioning by function (overlap and interactions), time (priority effects), environmental change over time (storage effects), and spatial variation in the environment (local adaptation). We describe how these processes can both hinder and facilitate plant microbiome treatments, which is also diagrammed in Figure 1 and examples are provided in Table 2.

Niche overlap and interactions. Understanding the fundamental and realized niche for fungal endophytes can facilitate designing mycobiome treatments that pass local environmental and host filters, as well as promote coexistence (Table 1) among members of the fungal community that are coinoculated. Determining fundamental niche dimensions for individual fungi and what niche space is actually occupied in the presence of other fungal taxa can be challenging due to complex fungal life cycles, fungal plasticity, and difficulty in measuring fungal fitness. We can, however, infer likely niche factors such as environmental and host preferences based on distributional data. Turnover of leaf endophyte taxa at regional to continental scales suggests partitioning by climate across multiple host plants (Giauque and Hawkes 2016; U'Ren et al. 2012; Zimmerman and Vitousek 2012). At smaller scales, two closely related endophyte taxa that inhabit roots of Phragmites australis were separated by niche preferences for dry versus flooded habitats (Ernst et al. 2011). Arbuscular mycorrhizal taxa in roots more frequently coexist (Maherali and Klironomos 2012) and maintain communities with more taxa (Maherali and Klironomos 2007) when the starting fungal species are more distantly related, consistent with reduced niche overlap (Table 1). Partitioning across host plants may likewise depend on host divergence: endophyte communities are often similar between related hosts (particularly grasses), and generally show increasing dissimilarity with host phylogenetic distance (Arnold and Lutzoni 2007; Giauque and Hawkes 2016; Higgins et al. 2014; Öpik et al. 2009; Wearn et al. 2012). Thus, climate, habitat, and host plant will likely need to be considered to some extent when designing field treatments.

When considering functional outcomes of species interactions in the microbiome, both niche overlap and complementarity (Table 1) can generate nonadditive effects via competition and facilitation (Cardinale et al. 2007). Microbes are known to produce unique metabolites and express unique sets of genes in cocultures compared with monocultures (Bertrand et al. 2014; Jonkers et al. 2012). Such interactions also scale up to effects on the plant host. In Panicum virgatum grown in drought conditions, the degree of nonadditivity in foliar endophyte interactions compared with the effects of individual endophytes depended on divergences in fungal metabolomic profiles; fungi with less similar metabolites had greater nonadditive benefits on host plant growth and wilt resistance (Connor et al. 2017). Additional interaction studies that address coexistence and effects on the host, carried out in planta, are much needed for microbiome treatment development.

Because niche processes are expected to control fungal community assembly and effects on the host, microbiome treatments should ideally account for both interactions within the treatment community and potential interactions with new taxa that arrive via dispersal. Niche overlap is already being considered in the development of endophyte treatments for biocontrol of pathogens (Blumenstein et al. 2015; Cavaglieri et al. 2004). For example, endophytes with carbon use profiles that overlap pathogens are likely to compete with those pathogens and potentially reduce infections. In addition, microbiome communities created to maximize niche occupancy may help make such treatments more resistant to invasion by new arrivals (Eisenhauer et al. 2013). To do so, however, requires an understanding of which niche dimensions are most important for symbiont interactions-plant carbon and space in the plant are two seemingly obvious niche factors for which microbiome taxa might compete, but others are likely to play a role.

Although the majority of plant microbiome studies focus on single taxa, experimental tests of niche overlap and interactions in cultures and in the greenhouse are a feasible method for determining optimal microbiome assemblages sourced from limited areas or focused on a subset of the microbiome such as endophytic fungi. However, scaling up to whole-plant microbiomes and from greenhouse patterns to regional or larger-scale field tests is challenging and costly, underscoring the importance of targeting consortia that have a higher probability of success. One potential approach to reduce the number of initial possible microbiome communities is to characterize the realized niche from biogeographic patterns of sequenced microbiomes, which provide information on the combination of ecological requirements and biotic interactions under which taxa exist in real-world ecosystems. Co-occurrence and mutual exclusion patterns of existing microbiomes can also be used to predict interactions (Berry and Widder 2014; Faust and Raes 2012) and form the basis for modeling initial microbial mixtures for application tests.

Combining microbial co-occurrence with models of genomic or metabolic networks can predict microbial niche overlap and associations of taxa, genes, and functions with the host condition. For example, a genome-scale metabolic modeling approach was combined with co-occurrence data by Zelezniak and colleagues (2015) for 800 communities characterized by $16 \mathrm{~S}$ rRNA across a wide array of habitats; the authors identified groups of co-occurring microbes that likely exchange metabolites and support community growth under nutrient limited conditions. The authors suggest that recurring groups of microbial taxa linked by cooperative behaviors represent a fundamental aspect of microbial community structure. Community network approaches can similarly advance our understanding of plant-microbiome interactions. A recent study of Arabidopsis thaliana phyllosphere microbes identified strongly interconnected "hub" taxa that had cascading effects on growth and diversity in the broader community (Agler et al. 2016). Such hub taxa could provide the basis for community microbiome treatments. In addition, co-occurrence, genomic, and metabolic patterns along environmental and temporal gradients may be useful for identifying resistant and resilient (Table 1) communities associated with various host states. Nevertheless, links must be established between modeled and actual function in the host. Methods are being developed to make the integration of co-occurrence, genomic, and metabolic network models a more accessible approach 
(Cao et al. 2016; Cardona et al. 2016; Hanemaaijer et al. 2017; MendesSoares et al. 2016; Zomorrodi and Maranas 2012).

Priority effects. The concept that order of arrival plays an important role in community assembly has a long history in ecology (Gleason 1926), with the expectation that priority effects (Table 1) occur through either niche preemption or niche modification (Fukami 2015). Consequently, variation in assembly order can result in diverse local communities occurring under the same environmental conditions (Chase 2003; Márquez and Kolasa 2013). For example, in root endophytes and arbuscular mycorrhizas, arrival order of both the plants and the fungi leads to divergent root fungal communities (Hausmann and Hawkes 2010; Sikes et al. 2016). Priority effects can act as a hindrance to microbiome treatments if nontarget taxa arrive first and preempt resources or alter the niche space, ultimately preventing treatments from successfully establishing (Fukami 2015). Conversely, applications of plant microbiome treatments could take advantage of priority effects to improve the probability of establishment success in field settings.

Priority for microbiome treatments can enhance establishment, persistence, and function. For example, fungi sprayed on newly emerged leaves may face no or few competitors while establishing. In plants as diverse as lima beans and elm trees, priority application of endophytic fungi inhibits infection by later-arriving pathogens (AdameÁlvarez et al. 2014; Miles et al. 2012). Some endophytes with priority allow subsequent colonization by other mutualists, but not by related pathogens (Redman et al. 2001); more generally, early-arriving species have more negative effects on more closely related species that arrive later (Peay et al. 2011). Moreover, increasing the lag between arrival of the first arbuscular mycorrhizal fungus and an invasive mycorrhizal

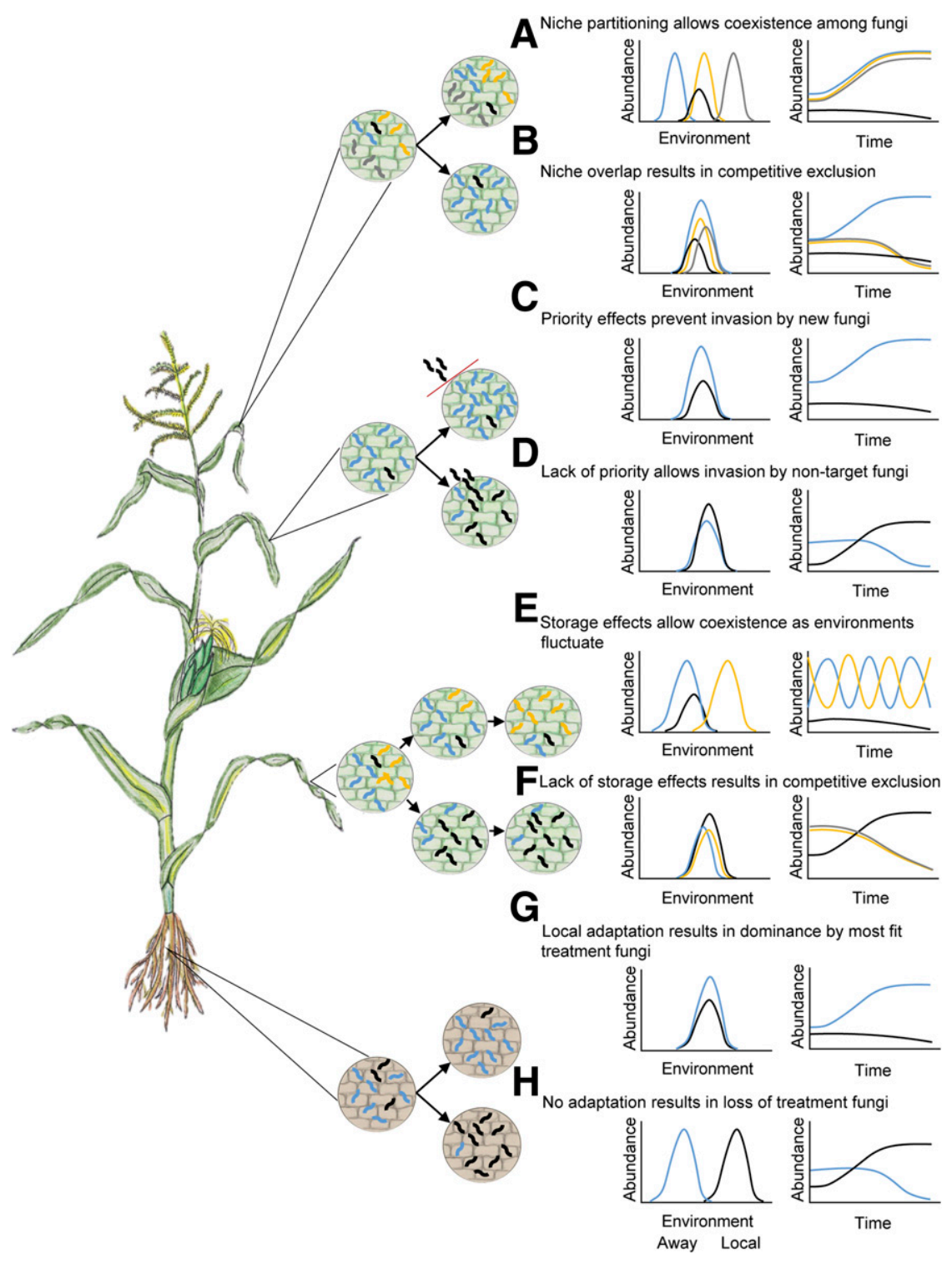

Fig. 1. Overview of mechanisms that can be exploited for (or act as a hindrance in) the implementation of plant microbiome treatments. A, Niche partitioning can reduce competition and facilitate coexistence and persistence of treatments. B, Niche overlap results in competitive exclusion by the most fit species in a given environment. C, Priority effects allow initial-arriving treatments to exclude later-arriving species. D, Lack of priority (simultaneous or later arrival) of microbiome treatments may prevent establishment due to competition with residents. E, Storage effects take advantage of temporal variation in niche availability to support species coexistence. $\mathbf{F}$, Lack of temporal variation in environmental conditions removes this dimension of niche space and may result in competitive exclusion. G, Local adaptation of microbiome treatments can allow taxa or consortia to exclude other microbes. $\mathbf{H}$, Mismatches between microbial adaptation and environmental conditions can result in loss of treatment taxa. Graphs in the left column indicate niche distributions of microbiome treatment taxa; graphs in the right column indicate species abundances in microbiome treatments (gray, blue, and yellow) relative to residents (black) over time that depend on niche distributions. Diagrams indicate these outcomes in the leaf. Maize drawing by Patrick Connor. 
TABLE 2

Examples of ecological processes at play in plant-associated endophytic fungi

\begin{tabular}{|c|c|c|c|}
\hline Fungi & Plant hosts & Outcome & Reference \\
\hline \multicolumn{4}{|l|}{ Niche partitioning } \\
\hline $\begin{array}{l}\text { Leaf endophyte community } \\
\text { composition }\end{array}$ & Pinus monticola & Varied by host stage and foliar nutrients & (Larkin et al. 2012) \\
\hline $\begin{array}{l}\text { Leaf endophyte community } \\
\text { composition }\end{array}$ & $\begin{array}{l}\text { Panicum hallii } \\
\text { Panicum virgatum }\end{array}$ & $\begin{array}{l}\text { Varied across rain gradient and with annual } \\
\text { weather }\end{array}$ & $\begin{array}{l}\text { (Giauque and Hawkes 2013, } \\
\text { 2016) }\end{array}$ \\
\hline $\begin{array}{l}\text { Root endophytes } \\
\text { Microdochium bolleyi } \\
\text { M. phragmitis } \\
\text { Stagonospora sp. and two } \\
\text { others }\end{array}$ & Phragmites australis & Habitat preferences (dry versus wet) & (Ernst et al. 2011) \\
\hline $\begin{array}{l}\text { Root endophyte community } \\
\text { composition }\end{array}$ & $\begin{array}{l}\text { Abies balsamea } \\
\text { Betula papyrifera } \\
\text { Picea glauca }\end{array}$ & $\begin{array}{l}\text { Some taxa with host preferences, others found on } \\
\text { all hosts }\end{array}$ & $\begin{array}{l}\text { (Kernaghan and Patriquin } \\
\text { 2011) }\end{array}$ \\
\hline $\begin{array}{l}\text { Arbuscular mycorrhizal fungal } \\
\text { communities }\end{array}$ & $\begin{array}{l}\text { Old field meadow and } \\
\text { Plantago lanceolata }\end{array}$ & $\begin{array}{l}\text { More distantly related taxa coexist more } \\
\text { frequently and have more diverse root } \\
\text { communities }\end{array}$ & $\begin{array}{l}\text { (Maherali and Klironomos 2007, } \\
\text { 2012) }\end{array}$ \\
\hline \multicolumn{4}{|l|}{ Priority effects } \\
\hline $\begin{array}{l}\text { Leaf endophytes } \\
\text { Aureobasidium pullulans } \\
\text { Paraconiothyrium sporulosum }\end{array}$ & $\begin{array}{l}\text { Solanum lycopersicum } \\
\text { 'Santa Clara' }\end{array}$ & $\begin{array}{l}\text { Preinoculation protected plants from Rhizoctonia } \\
\text { solani pathogens }\end{array}$ & (Miles et al. 2012) \\
\hline $\begin{array}{l}\text { Leaf endophyte } \\
\text { Colletotrichum spp. }\end{array}$ & Citrullus lanatus & $\begin{array}{l}\text { Inoculation with mutualist strain allowed } \\
\text { subsequent colonization by a mutualistic strain } \\
\text { but not a pathogenic strain }\end{array}$ & (Redman et al. 2001) \\
\hline $\begin{array}{l}\text { Leaf endophytes } \\
\text { Cochliobolus australiensis } \\
\text { Cochliobolus cynodontis } \\
\text { Fusarium sp. } 14201 \\
\text { Hyphozyma variabilis } \\
\text { Keissleriella genistae }\end{array}$ & Phaseolus lunatus & $\begin{array}{l}\text { Endophyte priority effects on disease depend on } \\
\text { both the endophyte and pathogen species }\end{array}$ & (Adame-Álvarez et al. 2014) \\
\hline Root endophyte communities & $\begin{array}{l}\text { Aristida gyrans } \\
\text { Schizachyrium niveum } \\
\text { Melinis repens }\end{array}$ & Interactions between plant and fungal priority & (Sikes et al. 2016) \\
\hline $\begin{array}{l}\text { Leaf and root endophyte } \\
\text { communities }\end{array}$ & $\begin{array}{l}\text { Cirsium arvense } \\
\text { Plantago lanceolata } \\
\text { Rumex acetosa } \\
\end{array}$ & $\begin{array}{l}\text { Abundance and diversity shifted among hosts and } \\
\text { seasons }\end{array}$ & (Wearn et al. 2012) \\
\hline $\begin{array}{l}\text { Arbuscular mycorrhizal fungi } \\
\text { Acaulospora colossica } \\
\text { Gigaspora gigantea }\end{array}$ & Temperate grassland & $\begin{array}{l}\text { Warm versus cool season separation of } \\
\text { sporulation }\end{array}$ & (Pringle and Bever 2002) \\
\hline $\begin{array}{l}\text { Arbuscular mycorrhizal fungal } \\
\text { communities }\end{array}$ & Temperate grassland & Seasonal changes in community composition & (Dumbrell et al. 2011) \\
\hline \multicolumn{4}{|l|}{ Local adaptation } \\
\hline $\begin{array}{l}\text { Leaf endophytes } \\
\text { Fusarium culmorum } \\
\text { Curvularia protuberata } \\
\text { Colletotrichum magna }\end{array}$ & $\begin{array}{l}\text { Leymus mollis } \\
\text { Dichanthelium lanuginosum } \\
\text { Oryza sativa } \\
\text { Solanum lycopersicum }\end{array}$ & $\begin{array}{l}\text { Fungi from extreme stress environments confer } \\
\text { stress benefits to hosts, magnitude depends on } \\
\text { host plant species; fungi from agricultural } \\
\text { systems confer disease resistance }\end{array}$ & $\begin{array}{l}\text { (Redman et al. 2011; Rodriguez } \\
\text { et al. 2008) }\end{array}$ \\
\hline $\begin{array}{l}\text { Arbuscular mycorrhizal fungi } \\
\text { Acaulospora elegans } \\
\text { Scutellospora calospora }\end{array}$ & $\begin{array}{l}\text { Artemisia tridentata ssp. } \\
\text { tridentata }\end{array}$ & $\begin{array}{l}\text { Higher fungal survivorship at site of origin } \\
\text { compared with nonhome site }\end{array}$ & (Weinbaum et al. 1996) \\
\hline $\begin{array}{l}\text { Arbuscular mycorrhizal fungal } \\
\text { communities }\end{array}$ & Andropogon gerardii & $\begin{array}{l}\text { Fungal community benefit to host is matched to } \\
\text { local resource availability }\end{array}$ & (Johnson 2010) \\
\hline $\begin{array}{l}\text { Arbuscular mycorrhizal fungal } \\
\text { communities }\end{array}$ & $\begin{array}{l}\text { Cynodon dactylon } \\
\text { Poa pratensis }\end{array}$ & $\begin{array}{l}\text { Fungi from different climate regions have different } \\
\text { host effects, but unaffected by experimental } \\
\text { temperature }\end{array}$ & (Antunes et al. 2011) \\
\hline
\end{tabular}


fungus decreases the success of invader establishment (Werner and Kiers 2015). Facilitating priority for belowground establishment may require seed or root dips given the ever-present nature of soil microbes and the challenges of root applications postplanting. Maximizing the time span between which microbiome treatments are applied and subsequently challenged by immigration may also be possible; for example, when seedlings are initiated in the greenhouse before transplantation outdoors.

However, when developing microbiome tools that take advantage of priority effects, we must also consider that these may be transient states (Fukami and Nakajima 2011); for example, turnover of the microbiome may occur as plants grow from seedling to juvenile to adult (Husband et al. 2002). In cases of transient states, priority effects may be leveraged to implement initial treatments that initiate a desired trajectory or are combined with other approaches targeting later stages. For example, because the strength of priority effects can depend on niche overlap or phylogenetic relatedness between early and later arriving taxa (Tan et al. 2012), stage-specific treatments might be designed to support invasion of later applications. Finally, environmental filtering can overcome assembly order when the filter is severe, such as under drought (Chase 2007), meaning that use of priority effects in microbiome treatment applications will likely work best when there is also a good environmental fit.

For some species and consortia, arriving first will always translate into competitive dominance; for others, however, priority in arrival will not prevent colonization by later-arriving species (Kennedy et al. 2009). Development of initial priority strategies may be informed by culture-based studies that elucidate potential indicators of niche preemption or niche modification and are likely to correlate with subsequent competitive dominance. Examples of potential priority indicators include traits representing competitive ability, habitat or resource modification, or resistance to invasion (e.g., growth rates, carbon use profiles, enzyme activities, and production of inhibitory metabolites). Saunders et al. (2010) screened endophytic fungi in culture for the ability to detoxify 2-benzoxazolinone, a common byproduct of maize defense compounds, finding that Fusarium species and other endophytes that could tolerate the toxin had a colonization advantage. Other studies of wood decay suggest that biochemical resource alteration or combative ability may play a role in fungal priority (Hiscox et al. 2015; Ottosson et al. 2014). Further studies that quantify how priority indicators in culture relate to priority effects in the plant are required to confirm that culturebased findings can be translated to in situ processes in the plant host.

Storage effects. The storage effect (Table 1) extends niche partitioning to fluctuating environments based on the idea that community dynamics can be regulated by niche opportunities that vary over time. For example, under intermittent abiotic stressors such as periodic drought, species with higher growth rates under ambient versus drier conditions will be alternately favored as conditions shift. For storage effects to occur, species' population densities must respond differently to the environment and resist extinction under unfavorable environments (e.g., via dormancy); given these conditions, fluctuating environments should limit competitive interactions and allow for coexistence (Warner and Chesson 1985). Though never applied to symbionts, the storage effect has been demonstrated in freeliving microbes in microcosms. For instance, variation in temperature over time allowed for coexistence of two diatom species that had different temperature optima (Descamps-Julien and Gonzalez 2005) and also overcame priority effects in bacteria and yeast nectar communities (Tucker and Fukami 2014). There are indications that the storage effect could contribute to variation in plant-associated microbial community composition and abundance over time. For example, fungal endophytes have different temperature and moisture requirements for optimal growth (Zhang et al. 2013), which should facilitate shifts in species abundances over time as the environment changes. Environmental regulation of symbiotic fungal species abundances is further supported by observed seasonal shifts in community composition of both foliar endophytes and arbuscular mycorrhizas (Dumbrell et al. 2011; Unterseher et al. 2007; Wearn et al. 2012), although specific temporal patterns can be site-specific as observed for cotton endophytes (Ek-Ramos et al. 2013). However, seasonal sampling does not capture how the microbiome might respond to critical environmental stress events during a given season.

The storage effect is particularly appealing as a tool in systems where symbiotic fungi both differentially contribute to plant growth versus stress responses and have different environmental tolerances. One possibility is for fungi that promote plant growth under optimal conditions to be paired with fungi that enable survival under stressed conditions, with fungal coexistence supported when the abundance of each species is also linked to their function under these environmental conditions. Conversely, if fungi contribute the same benefit but are abundant under different environments, the storage effect could be exploited to create functionally stable microbiome communities that are continually active. Given this potential, the storage effect is worth further study as a tool for manipulating plant microbiomes despite the difficulty in parsing the role of multiple environmental variables in controlling fungal abundances (Giauque and Hawkes 2016).

Identifying how environmental fluctuations affect niche conditions relevant for microbial symbionts is nevertheless challenging because the phytobiome environment is highly dynamic. Plant photosynthesis, for example, will vary across daily to seasonal to annual time scales (and presumably thereby create different niche opportunities by affecting carbon supplies for microbial symbionts). Thus, exploiting environmental variability may only be feasible in sites that have a few, strong forces driving differential patterns among taxa in how growth depends on the environment. For example, fungal communities in grasslands are largely regulated by temperature and precipitation, allowing for potential niche separation over time as these two factors vary (Dumbrell et al. 2011; Giauque and Hawkes 2016); similar temporal niche variation should occur in low-input agricultural systems dependent on water from rainfall. Furthermore, storage effects will only occur when population growth rates are high enough to both limit invasion by new species under favorable conditions and sustain populations during unfavorable times. Although treatment applications can overcome this limitation with high levels of inoculation, Verbruggen et al. (2013) estimated that 7 tons per hectare of arbuscular mycorrhizal fungi would be needed to match native population densities in agricultural systems. Therefore, this approach may be more suited for situations where microbiome treatments can be applied to newly emerged leaf tissues, which would also allow for integration of priority and storage effects. In addition, persistence of fungi through periods of suboptimal conditions can be enhanced by selecting fungal taxa that invest in spore production and have rapid growth rates during recovery.

Local adaptation. Although evolution of populations to be more suited to local environments (i.e., local adaptation; Table 1) is well known for macroorganisms, historically, microorganisms were thought to have widespread dispersal with largely cosmopolitan species and no local adaptation (Martiny et al. 2006). The topic remains somewhat controversial (Bruns and Taylor 2016; Davison et al. 2015), but recent studies demonstrate dispersal limitation and endemism (Table 1) in fungal taxa (Adams et al. 2013) that supports potential local adaptation. Indeed, there is good experimental evidence for adaptation of fungi to local environmental factors and biotic interactions. For example, arbuscular mycorrhizal fungi are specialized to local soil resources (Johnson 2010) and climate (Antunes et al. 2011), with declining populations over time when moved to new locations (Weinbaum et al. 1996). In addition, as 
indicated earlier in regard to habitat-adapted fungi, fungal endophytes from high-stress locations confer benefits to distantly related host plants consistent with local adaptation to environment rather than host (Redman et al. 2011; Rodriguez et al. 2008). There is also an extensive literature documenting local adaptation of pathogens to host plants (reviewed in Kraemer and Boynton 2017). If local adaptation proves to be widespread for beneficial microbiota, then treatment development will require a local or regional focus, or one that matches environments to fungal fitness.

Exploitation of existing local adaptation for microbiome treatment development can support persistent microbial communities that resist arrival of later immigrants, including those that are preadapted to the local conditions (Vanoverbeke et al. 2016). Conversely, breaking the structure of local adaptation by moving taxa into novel hosts or habitats can undermine microbiome treatments unless conditions are well matched to fungal optima. Habitat-adaptation, for instance, might be exploited beyond the site of origin to sites with similar selective conditions. However, any specialization to host, climate, or edaphic factors constrains the scope of microbiome treatment applications. Additional study is required before our understanding of microbiome adaptation will be on par with plants, including the potential to extrapolate geographically to adaptation regions (Vogel et al. 2005).

Existing local adaptation is not necessarily static, as contemporary forces can drive ongoing evolution. Rapid local adaptation of taxa in microbiome treatments can act as a boon (selection for reinforcement) or a hindrance (selection that shifts function away from targets). Little is known about the rate of adaptation in endophytes, but rapid adaptation of other microbial taxa has been shown in cultures and microcosms (Bell and Gonzalez 2009; Pantel et al. 2015; Wiser et al. 2013). Given that many endophytic fungi have complex life cycles spent partly as symbionts and partly free-living, multiple selective regimes may constrain the rate of evolution in response to single environmental factors. Nevertheless, evolutionary stability is likely to be short term for many microbes.

Detection of local adaptation requires the demonstration of a genotype-environment interaction, where the target microbial population has higher fitness in its local habitat compared with immigrants to that habitat (Kawecki and Ebert 2004). Common approaches to test local adaptation include field reciprocal transplants, common garden experiments, and similar lab tests where key habitat properties are manipulated. For example, Antunes et al. (2011) tested for temperature adaptation of arbuscular mycorrhizal fungi by growing pairs of conspecific isolates from different climates at two temperatures. Fungal growth was not affected by temperature, but isolates from cool versus warm origins differentially affected plant growth (Antunes et al. 2011). Demonstrating microbial fitness can be challenging for fungi, but growth rate is often considered a suitable proxy. However, when studying the outcome of symbiosis with the goal of agricultural management, we are more interested in how locally adapted microbiome taxa affect the fitness of the plant host compared with those that are not locally adapted. For instance, generalist taxa or communities that can grow well in multiple conditions may confer similar but lower benefits regardless of environment while local specialists that grow best under limited conditions may provide larger benefits under some environments and smaller benefits under others. Understanding these potential contrasts will be important in determining which microbiome treatments are selected and when they are applied.

\section{BARRIERS TO MICROBIOME TREATMENT DEVELOPMENT AND APPLICATIONS}

Despite the expected dominance of deterministic niche processes, neutral processes (Table 1) are also likely to contribute to microbiome communities, which can affect treatment applications. In contrast to niche theory, a neutral/stochastic framework assumes that all species are ecologically identical, such that differences in community composition and diversity are due to random colonization, extinction, and drift (Hubbell 2001). For example, stochastic colonization and extinction dynamics are expected when the regional species pool is substantially larger than the local community (Chase and Myers 2011). Microbes are often assumed to have enormous diversity and abundance in the regional pool due to widespread dispersal of spores, but recent work suggests dispersal limitation, endemism, and local adaptation are common (Adams et al. 2013; Antunes et al. 2011; Johnson 2010). Few studies have explicitly addressed the contribution of neutral processes to the assembly of fungal endophyte communities. Using distance-decay patterns (Table 1), Goldmann et al. (2016) inferred that root-associated fungal communities were less subject to neutral processes compared with soil fungal communities. At global scales, arbuscular mycorrhizal fungal communities are generally associated with environmental conditions and plant communities (Davison et al. 2015; Kivlin et al. 2011); however, when global data are analyzed within habitats, community patterns were better explained by neutral or stochastic processes (Powell and Bennett 2016).

The relative importance of neutral versus niche processes remains an area of active study and continued debate, but stochasticity will play some role (Chase and Myers 2011). For example, we should expect microbiome treatments to be continually challenged by immigration with some random colonization success and to face random extinction events even when optimized for the existing niche space. Treatments can be built to minimize these effects by taking advantage of niche processes that create resistance and/or resilience (Table 1) of the treatment community to invasion. Treatments that are designed to be resistant or resilient will persist or rapidly recover their composition and function in the face of immigration challenges; niche processes can be leveraged to maximize resistance/ resilience while minimizing colonization success by maximizing niche occupancy. In addition, repeated microbial applications may be used to shift the balance away from the local species pool and toward the applied microbiome, as well as to overcome stochastic extinction or colonization events that may alter the target treatment. Plant microbiome treatment development must therefore consider the combination of niche and neutral processes at play: effective microbiome treatments will work in the context of the environment, existing microbial communities, microbial immigration, and stochasticity (Cottenie 2005; Kinkel et al. 1989).

Progress is rapidly being made in our understanding of the plant microbiome, but we still lack sufficient basic data on microbial biology in situ to quickly develop widespread, ecologically robust treatments. Current industry applications are typically focused on single microbial taxa paired with individual crops, such as BioEnsure Corn and Rice (Adaptive Symbiotic Technologies) and Indigo Cotton (IndigoAg). We argue here that the future of microbiome treatments needs a community context, both in terms of assembling treatment consortia that can coexist and applying treatments that will persist in the context of resident microbiota in the plant host. To optimize microbiome treatments from a niche perspective requires more information on the microbes, which can be provided in part by high throughput screening of microbial taxa and their functions in symbiosis under an array of experimental conditions and in diverse communities. However, to reduce the scope of screening required when selecting putatively beneficial microbes that often fail to provide benefits in field settings, we can narrow our choices by considering predictions from the ecological processes described herein. The question of potential unintended consequences of microbial introductions must also be addressed when microbiome treatments are developed from nonlocal taxa. 
Other limitations are technological. For instance, the use of microbial genomes is likely to be increasingly helpful for forecasting function and treatment development as more genomes are sequenced and added to public databases. However, definitively linking genes to function is a long process, requiring tools from ecology, physiology, and molecular biology. We also require an understanding of intraspecific genomic variation in order to build a framework that successfully accounts for local genotypes.

Finally, the application of microbial amendments at large-scales is still in its infancy and optimal crop-specific application strategies have yet to be developed. Current methods for endophyte applications include seed coatings (Pedrini et al. 2017) that can be used to create priority for target fungi. Typical seed coating methods include spores, conidia, or hyphae applied as dustings or suspensions in water, oil, or polymers (O'Callaghan 2016). Microbial seed coatings may be combined with other coatings that benefit seed germination and seedling vigor, such as hydrogels and growth promoters, but these mixtures will need to be tested. Vertically transmitted symbionts or early seed colonizers also present an option for delivery internal to the seed. An alternative is direct spraying of endophytic fungal inoculum onto leaves, which can be timed to create priority on new vegetation or repeated throughout the growing season as a way to mitigate competitive superiority of locally adapted populations that might otherwise drive treatment taxa to extinction.

Obligate symbiotic mycorrhizal fungi are added as spores or colonized root fragments in soil inoculum, typically obtained from cost-effective cultivation of a single host plant in soil- or substratebased production systems; substrate-free and root organ culture methods that produce contaminant-free propagules have been developed, but are still relatively expensive (IJdo et al. 2011). Although soil inocula will always compete with the existing soil microbial community, single applications can result in important transient effects or might initiate specific microbial community trajectories. For example, only 1 out of 24 root endophytes was detectable after 6 months in the greenhouse even for fungi that were given priority, but nevertheless the original inocula affected plant emergence and final biomass (Sikes et al. 2016).

\section{CONCLUSIONS}

The plant microbiome is a clear target for agronomic development and fungal endophytes in particular are likely to be successful tools for improving plant growth and stress tolerance in ways that complement traditional plant breeding approaches. Industry is already leading the charge for scaling up and high throughput phenotyping. However, most of this work has focused on single species applications. Future research in a community context, from genes to physiology, will be needed for microbiomes to become a commonplace fixture in our agricultural toolkits. We focused on fungal endophytes here, but the entire phytobiome, including interactions with viruses, bacteria, arthropods, nematodes, and so forth (Hartley and Gange 2009), will also play a role in treatment efficacy and thus integration across these components is much needed. The niche processes that we review here are examples of ways that ecology and evolution of plant-associated biota can be harnessed to increase the success of translating phytobiome communities from the lab to the real world.

\section{ACKNOWLEDGMENTS}

Previous drafts of this manuscript were improved by comments from C. Young and M. Sandy. The ideas herein were developed as part of a project supported by the Agriculture and Food Research
Initiative competitive grant 2017-67013-26196 of the USDA National Institute of Food and Agriculture.

\section{LITERATURE CITED}

Ackerly, D. 2009. Conservatism and diversification of plant functional traits: Evolutionary rates versus phylogenetic signal. Proc. Natl. Acad. Sci. 106: 19699-19706.

Adame-Álvarez, R.-M., Mendiola-Soto, J., and Heil, M. 2014. Order of arrival shifts endophyte-pathogen interactions in bean from resistance induction to disease facilitation. FEMS Microbiol. Lett. 355:100-107.

Adams, R. I., Miletto, M., Taylor, J. W., and Bruns, T. D. 2013. Dispersal in microbes: Fungi in indoor air are dominated by outdoor air and show dispersal limitation at short distances. ISME J. 7:1262-1273.

Adler, P. B., Fajardo, A., Kleinhesselink, A. R., and Kraft, N. J. B. 2013. Trait-based tests of coexistence mechanisms. Ecol. Lett. 16:1294-1306.

Agler, M. T., Ruhe, J., Kroll, S., Morhenn, C., Kim, S.-T., Weigel, D., and Kemen, E. M. 2016. Microbial hub taxa link host and abiotic factors to plant microbiome variation. PLoS Biol. 14:e1002352.

Angelard, C., Tanner, C. J., Fontanillas, P., Niculita-Hirzel, H., Masclaux, F., and Sanders, I. R. 2014. Rapid genotypic change and plasticity in arbuscular mycorrhizal fungi is caused by a host shift and enhanced by segregation. ISME J. 8:284-294

Antunes, P. M., Koch, A. M., Morton, J. B., Rillig, M. C., and Klironomos, J. N. 2011. Evidence for functional divergence in arbuscular mycorrhizal fungi from contrasting climatic origins. New Phytol. 189:507-514.

Arnold, A. E., and Engelbrecht, B. M. J. 2007. Fungal endophytes nearly double minimum leaf conductance in seedlings of a neotropical tree species. J. Trop. Ecol. 23:369-372.

Arnold, A. E., and Lutzoni, F. 2007. Diversity and host range of foliar fungal endophytes: Are tropical leaves biodiversity hotspots? Ecology 88:541-549.

Arnold, A. E., Mejia, L. C., Kyllo, D., Rojas, E. I., Maynard, Z., Robbins, N., and Herre, E. A. 2003. Fungal endophytes limit pathogen damage in a tropical tree. Proc. Natl. Acad. Sci. USA 100:15649-15654.

Bell, G., and Gonzalez, A. 2009. Evolutionary rescue can prevent extinction following environmental change. Ecol. Lett. 12:942-948.

Berry, D., and Widder, S. 2014. Deciphering microbial interactions and detecting keystone species with co-occurrence networks. Front. Microbiol. 5:219.

Bertrand, S., Azzollini, A., Schumpp, O., Bohni, N., Schrenzel, J., Monod, M., Gindro, K., and Wolfender, J.-L. 2014. Multi-well fungal co-culture for de novo metabolite-induction in time-series studies based on untargeted metabolomics. Mol. Biosyst. 10:2289-2298.

Blumenstein, K., Albrectsen, B. R., Martín, J. A., Hultberg, M., Sieber, T. N., Helander, M., and Witzell, J. 2015. Nutritional niche overlap potentiates the use of endophytes in biocontrol of a tree disease. BioControl 60:655-667.

Bruns, T. D., and Taylor, J. W. 2016. Comment on "Global assessment of arbuscular mycorrhizal fungus diversity reveals very low endemism”. Science 351:826.

Cao, Y., Wang, Y., Zheng, X., Li, F., and Bo, X. 2016. RevEcoR: An R package for the reverse ecology analysis of microbiomes. BMC Bioinformatics 17:294.

Cardinale, B. J., Wright, J. P., Cadotte, M. W., Carroll, I. T., Hector, A., Srivastava, D. S., Loreau, M., and Weis, J. J. 2007. Impacts of plant diversity on biomass production increase through time because of species complementarity. Proc. Natl. Acad. Sci. 104:18123-18128.

Cardona, C., Weisenhorn, P., Henry, C., and Gilbert, J. A. 2016. Network-based metabolic analysis and microbial community modeling. Curr. Opin. Microbiol. 31:124-131.

Carroll, G. 1988. Fungal endophytes in stems and leaves: From latent pathogen to mutualistic symbiont. Ecology 69:2-9.

Carroll, G., and Petrini, O. 1983. Patterns of substrate utilization by some fungal endophytes from coniferous foliage. Mycologia 75:53-63.

Castillo Lopez, D., Zhu-Salzman, K., Ek-Ramos, M. J., and Sword, G. A. 2014. The entomopathogenic fungal endophytes Purpureocillium lilacinum (formerly Paecilomyces lilacinus) and Beauveria bassiana negatively affect cotton aphid reproduction under both greenhouse and field conditions. PLoS One 9: e103891.

Cavaglieri, L. R., Passone, A., and Etcheverry, M. G. 2004. Correlation between screening procedures to select root endophytes for biological control of Fusarium verticillioides in Zea mays L. Biol. Control 31:259-267.

Chagnon, P.-L., Bradley, R. L., Maherali, H., and Klironomos, J. N. 2013. A trait-based framework to understand life history of mycorrhizal fungi. Trends Plant Sci. 18:484-491. 
Challinor, A. J., Watson, J., Lobell, D. B., Howden, S. M., Smith, D. R., and Chhetri, N. 2014. A meta-analysis of crop yield under climate change and adaptation. Nat. Clim. Chang. 4:287-291.

Chase, J. M. 2003. Community assembly: When should history matter? Oecologia 136:489-498.

Chase, J. M. 2007. Drought mediates the importance of stochastic community assembly. Proc. Natl. Acad. Sci. 104:17430-17434.

Chase, J. M., and Leibold, M. A. 2009. Ecological Niches. University of Chicago Press, Chicago, IL.

Chase, J. M., and Myers, J. A. 2011. Disentangling the importance of ecological niches from stochastic processes across scales. Philos. Trans. Roy. Soc. B. Biol. Sci. 366:2351-2363.

Chesson, P. 2000. Mechanisms of maintenance of species diversity. Annu. Rev. Ecol. Syst. 31:343-366.

Connor, E. W., Sandy, M., and Hawkes, C. V. 2017. Microbial tools in agriculture require an ecological context: Stress-dependent non-additive symbiont interactions. Agron. J. 109:1-10.

Cottenie, K. 2005. Integrating environmental and spatial processes in ecological community dynamics. Ecol. Lett. 8:1175-1182.

Crisp, M. D., Laffan, S., Linder, H. P., and Monro, A. 2001. Endemism in the Australian flora. J. Biogeogr. 28:183-198.

Crowther, T. W., Maynard, D. S., Crowther, T. R., Peccia, J., Smith, J. R., and Bradford, M. A. 2014. Untangling the fungal niche: The trait-based approach. Front. Microbiol. 5:579.

Davison, J., Moora, M., Öpik, M., Adholeya, A., Ainsaar, L., Bâ, A., Burla, S., Diedhiou, A. G., Hiiesalu, I., Jairus, T., Johnson, N. C., Kane, A., Koorem, K., Kochar, M., Ndiaye, C., Pärtel, M., Reier, Ü., Saks, Ü., Singh, R., Vasar, M., and Zobel, M. 2015. Global assessment of arbuscular mycorrhizal fungus diversity reveals very low endemism. Science 349:970-973.

Delaye, L., García-Guzmán, G., and Heil, M. 2013. Endophytes versus biotrophic and necrotrophic pathogens-Are fungal lifestyles evolutionarily stable traits? Fungal Divers. 60:125-135.

Descamps-Julien, B., and Gonzalez, A. 2005. Stable coexistence in a fluctuating environment: An experimental demonstration. Ecology 86:2815-2824.

Dobzhansky, T. 1937. Genetics and the Origin of Species. Columbia University Press, New York.

Dumbrell, A. J., Ashton, P. D., Aziz, N., Feng, G., Nelson, M., Dytham, C., Fitter, A. H., and Helgason, T. 2011. Distinct seasonal assemblages of arbuscular mycorrhizal fungi revealed by massively parallel pyrosequencing. New Phytol. 190:794-804.

Eisenhauer, N., Schulz, W., Scheu, S., and Jousset, A. 2013. Niche dimensionality links biodiversity and invasibility of microbial communities. Funct. Ecol. 27:282-288.

Ek-Ramos, M. J., Zhou, W., Valencia, C. U., Antwi, J. B., Kalns, L. L., Morgan, G. D., Kerns, D. L., and Sword, G. A. 2013. Spatial and temporal variation in fungal endophyte communities isolated from cultivated cotton Gossypium hirsutum. PLoS One 8:e66049.

Ernst, M., Neubert, K., Mendgen, K. W., and Wirsel, S. G. 2011. Niche differentiation of two sympatric species of Microdochium colonizing the roots of common reed. BMC Microbiol. 11:242.

Farrar, K., Bryant, D., and Cope-Selby, N. 2014. Understanding and engineering beneficial plant-microbe interactions: Plant growth promotion in energy crops. Plant Biotechnol. J. 12:1193-1206.

Faust, K., and Raes, J. 2012. Microbial interactions: From networks to models. Nat. Rev. Microbiol. 10:538-550.

Fierer, N., Barberán, A., and Laughlin, D. C. 2014. Seeing the forest for the genes: Using metagenomics to infer the aggregated traits of microbial communities. Front. Microbiol. 5:614.

Fukami, T. 2015. Historical contingency in community assembly: Integrating niches, species pools, and priority effects. Annu. Rev. Ecol. Evol. Syst. 46: $1-23$

Fukami, T., and Nakajima, M. 2011. Community assembly: Alternative stable states or alternative transient states? Ecol. Lett. 14:973-984.

Gause, G. 1934. The Struggle for Existence. Williams and Wilkins, Baltimore, MD.

Giauque, H., and Hawkes, C. V. 2013. Climate affects symbiotic fungal endophyte diversity and performance. Am. J. Bot. 100:1435-1444

Giauque, H., and Hawkes, C. V. 2016. Historical and current climate drive spatial and temporal patterns in fungal endophyte diversity. Fungal Ecol. 20: 108-114.

Giauque, H. E. 2016. Hierarchical controls of endophyte-mediated drought tolerance: Ecological, physiological, and molecular. The University of Texas at Austin, Austin, TX.

Gleason, H. A. 1926. The individualistic concept of the plant association. Bull. Torrey Bot. Club 53:7-26.
Goh, C.-H., Veliz Vallejos, D. F., Nicotra, A. B., and Mathesius, U. 2013. The impact of beneficial plant-associated microbes on plant phenotypic plasticity. J. Chem. Ecol. 39:826-839.

Goldmann, K., Schröter, K., Pena, R., Schöning, I., Schrumpf, M., Buscot, F., Polle, A., and Wubet, T. 2016. Divergent habitat filtering of root and soil fungal communities in temperate beech forests. Sci. Rep. 6:31439.

Govinda Rajulu, M. B., Thirunavukkarasu, N., Suryanarayanan, T. S., Ravishankar, J. P., El Gueddari, N. E., and Moerschbacher, B. M. 2011. Chitinolytic enzymes from endophytic fungi. Fungal Divers. 47:43-53.

Grigoriev, I. V., Nikitin, R., Haridas, S., Kuo, A., Ohm, R., Otillar, R., Riley, R., Salamov, A., Zhao, X., Korzeniewski, F., Smirnova, T., Nordberg, H., Dubchak, I., and Shabalov, I. 2014. MycoCosm portal: Gearing up for 1000 fungal genomes. Nucleic Acids Res. 42:D699-D704.

Hamilton, C. E., Gundel, P. E., Helander, M., and Saikkonen, K. 2012. Endophytic mediation of reactive oxygen species and antioxidant activity in plants: A review. Fungal Divers. 54:1-10.

Hanemaaijer, M., Olivier, B. G., Röling, W. F. M., Bruggeman, F. J., and Teusink, B. 2017. Model-based quantification of metabolic interactions from dynamic microbial-community data. PLoS One 12:e0173183.

Hartley, S. E., Eschen, R., Horwood, J. M., Gange, A. C., and Hill, E. M. 2015. Infection by a foliar endophyte elicits novel arabidopside-based plant defense reactions in its host, Cirsium arvense. New Phytol. 205:816-827.

Hartley, S. E., and Gange, A. C. 2009. Impacts of plant symbiotic fungi on insect herbivores: Mutualism in a multitrophic context. Annu. Rev. Entomol. 54: 323-342.

Hausmann, N. T., and Hawkes, C. V. 2010. Order of plant host establishment alters the composition of arbuscular mycorrhizal communities. Ecology 91:2333-2343.

Higgins, K. L., Arnold, A. E., Coley, P. D., and Kursar, T. A. 2014. Communities of fungal endophytes in tropical forest grasses: Highly diverse host- and habitat generalists characterized by strong spatial structure. Fungal Ecol. 8:1-11.

Hiscox, J., Savoury, M., Muller, C. T., Lindahl, B. D., Rogers, H. J., and Boddy, L. 2015. Priority effects during fungal community establishment in beech wood. ISME J. 9:2246-2260.

Hubbell, S. P. 2001. The Unified Neutral Theory of Biodiversity and Biogeography. Princeton University Press, Princeton, NJ.

Husband, R., Herre, E. A., and Young, J. P. W. 2002. Temporal variation in the arbuscular mycorrhizal communities colonizing seedlings in a tropical forest. FEMS Microbiol. Ecol. 42:131-136.

Hutchinson, G. E. 1957. Concluding remarks. Cold Spring Harbor Symp. Quant. Biol. 22:415-427.

IJdo, M., Cranenbrouck, S., and Declerck, S. 2011. Methods for large-scale production of AM fungi: Past, present, and future. Mycorrhiza 21:1-16.

Jiang, Y., Xiong, X., Danska, J., and Parkinson, J. 2016. Metatranscriptomic analysis of diverse microbial communities reveals core metabolic pathways and microbiome-specific functionality. Microbiome 4:2.

Johnson, N. C. 2010. Resource stoichiometry elucidates the structure and function of arbuscular mycorrhizas across scales. New Phytol. 185:631-647.

Johnson, N. C., Wilson, G. W. T., Wilson, J. A., Miller, R. M., and Bowker, M. A. 2015. Mycorrhizal phenotypes and the Law of the Minimum. New Phytol. 205: 1473-1484.

Jonkers, W., Rodriguez Estrada, A. E., Lee, K., Breakspear, A., May, G., and Kistler, H. C. 2012. Metabolome and transcriptome of the interaction between Ustilago maydis and Fusarium verticillioides in vitro. Appl. Environ. Microbiol. 78:3656-3667.

Jumpponen, A. 2001. Dark septate endophytes-Are they mycorrhizal? Mycorrhiza 11:207-211.

Kawecki, T. J., and Ebert, D. 2004. Conceptual issues in local adaptation. Ecol. Lett. 7:1225-1241

Kennedy, P. G., Peay, K. G., and Bruns, T. D. 2009. Root tip competition among ectomycorrhizal fungi: Are priority effects a rule or an exception? Ecology 90:2098-2107.

Kernaghan, G., and Patriquin, G. 2011. Host associations between fungal root endophytes and boreal trees. Microb. Ecol. 62:460-473.

Kia, S. H., Glynou, K., Nau, T., Thines, M., Piepenbring, M., and Maciá-Vicente, J. G. 2016. Influence of phylogenetic conservatism and trait convergence on the interactions between fungal root endophytes and plants. ISME J. 11:777-790.

Kinkel, L. L., Andrews, J. H., and Nordheim, E. V. 1989. Fungal immigration dynamics and community development on apple leaves. Microbiol. Ecol. 18: 45-58.

Kivlin, S. N., Hawkes, C. V., and Treseder, K. K. 2011. Global diversity and distribution of arbuscular mycorrhizal fungi. Soil Biol. Biochem. 43: 2294-2303. 
Kraemer, S. A., and Boynton, P. J. 2017. Evidence for microbial local adaptation in nature. Mol. Ecol. 26:1860-1876.

Kraft, N. J. B., and Ackerly, D. D. 2014. Assembly of plant communities. Pages 67-88 in: Ecology and the Environment. R. K. Monson, ed. Springer, New York.

Kumar, V., Baweja, M., Singh, P. K., and Shukla, P. 2016. Recent developments in systems biology and metabolic engineering of plant-microbe interactions. Front. Plant Sci. 7:1421.

Larkin, B. G., Hunt, L. S., and Ramsey, P. W. 2012. Foliar nutrients shape fungal endophyte communities in Western white pine (Pinus monticola) with implications for white-tailed deer herbivory. Fungal Ecol. 5:252-260.

Leibold, M. A., Holyoak, M., Mouquet, N., Amarasekare, P., Chase, J. M., Hoopes, M. F., Holt, R. D., Shurin, J. B., Law, R., Tilman, D., Loreau, M., and Gonzalez, A. 2004. The metacommunity concept: A framework for multiscale community ecology. Ecol. Lett. 7:601-613.

Longoni, P., Rodolfi, M., Pantaleoni, L., Doria, E., Concia, L., Picco, A. M., and Cella, R. 2012. Functional analysis of the degradation of cellulosic substrates by a Chaetomium globosum endophytic isolate. Appl. Environ. Microbiol. 78: 3693-3705.

Loreau, M., and Hector, A. 2001. Partitioning selection and complementarity in biodiversity experiments. Nature 412:72-76.

Macarthur, R., and Levins, R. 1967. The limiting similarity, convergence, and divergence of coexisting species. Am. Nat. 101:377-385.

Maherali, H., and Klironomos, J. N. 2007. Influence of phylogeny on fungal community assembly and ecosystem functioning. Science 316:1746-1748.

Maherali, H., and Klironomos, J. N. 2012. Phylogenetic and trait-based assembly of arbuscular mycorrhizal fungal communities. PLoS One 7:e36695.

Mandyam, K., Fox, C., and Jumpponen, A. 2012. Septate endophyte colonization and host responses of grasses and forbs native to a tallgrass prairie. Mycorrhiza 22:109-119.

Márquez, J. C., and Kolasa, J. 2013. Local and regional processes in community assembly. PLoS One 8:e54580.

Martiny, J. B. H., Bohannan, B. J. M., Brown, J. H., Colwell, R. K., Fuhrman, J. A., Green, J. L., Horner-Devine, M. C., Kane, M., Krumins, J. A., Kuske, C. R., Morin, P. J., Naeem, S., Ovreas, L., Reysenbach, A.-L., Smith, V. H., and Staley, J. T. 2006. Microbial biogeography: Putting microorganisms on the map. Nat. Rev. Microbiol. 4:102-112.

Martiny, J. B. H., Jones, S. E., Lennon, J. T., and Martiny, A. C. 2015. Microbiomes in light of traits: A phylogenetic perspective. Science 350: aac9323.

Mendes-Soares, H., Mundy, M., Soares, L. M., and Chia, N. 2016. MMinte: An application for predicting metabolic interactions among the microbial species in a community. BMC Bioinformatics 17:343.

Miles, L. A., Lopera, C. A., González, S., de García, M. C. C., Franco, A. E., and Restrepo, S. 2012. Exploring the biocontrol potential of fungal endophytes from an Andean Colombian Paramo ecosystem. BioControl 57:697-710.

Mueller, U. G., and Sachs, J. L. 2015. Engineering microbiomes to improve plant and animal health. Trends Microbiol. 23:606-617.

Newsham, K. K. 2011. A meta-analysis of plant responses to dark septate root endophytes. New Phytol. 190:783-793.

Nicotra, A. B., Atkin, O. K., Bonser, S. P., Davidson, A. M., Finnegan, E. J., Mathesius, U., Poot, P., Purugganan, M. D., Richards, C. L., Valladares, F., and van Kleunen, M. 2010. Plant phenotypic plasticity in a changing climate. Trends Plant Sci. 15:684-692.

O'Callaghan, M. 2016. Microbial inoculation of seed for improved crop performance: Issues and opportunities. Appl. Microbiol. Biotechnol. 100: 5729-5746.

Oelmüller, R., Sherameti, I., Tripathi, S., and Varma, A. 2009. Piriformospora indica, a cultivable root endophyte with multiple biotechnological applications. Symbiosis 49:1-17.

Öpik, M., Metsis, M., Daniell, T. J., Zobel, M., and Moora, M. 2009. Largescale parallel 454 sequencing reveals host ecological group specificity of arbuscular mycorrhizal fungi in a boreonemoral forest. New Phytol. 184: 424-437.

Ottosson, E., Nordén, J., Dahlberg, A., Edman, M., Jönsson, M., Larsson, K.-H., Olsson, J., Penttilä, R., Stenlid, J., and Ovaskainen, O. 2014. Species associations during the succession of wood-inhabiting fungal communities. Fungal Ecol. 11:17-28.

Pantel, J. H., Duvivier, C., and Meester, L. D. 2015. Rapid local adaptation mediates zooplankton community assembly in experimental mesocosms. Ecol. Lett. 18:992-1000.

Peay, K. G., Belisle, M., and Fukami, T. 2011. Phylogenetic relatedness predicts priority effects in nectar yeast communities. Proc. Biol. Sci. 279:749-758.
Pedrini, S., Merritt, D. J., Stevens, J., and Dixon, K. 2017. Seed coating: Science or marketing spin? Trends Plant Sci. 22:106-116.

Petrini, O., Sieber, T. N., Toti, L., and Viret, O. 1993. Ecology, metabolite production, and substrate utilization in endophytic fungi. Nat. Toxins 1:185-196.

Pimm, S. L. 1984. The complexity and stability of ecosystems. Nature 307:321-326.

Powell, J. R., and Bennett, A. E. 2016. Unpredictable assembly of arbuscular mycorrhizal fungal communities. Pedobiologia (Jena) 59:11-15.

Powell, J. R., Parrent, J. L., Hart, M. M., Klironomos, J. N., Rillig, M. C., and Maherali, H. 2009. Phylogenetic trait conservatism and the evolution of functional trade-offs in arbuscular mycorrhizal fungi. Proc. Biol. Sci. 276: 4237-4245.

Pringle, A., and Bever, J. D. 2002. Divergent phenologies may facilitate the coexistence of arbuscular mycorrhizal fungi in a North Carolina grassland. Am. J. Bot. 89:1439-1446.

Redman, R. S., Dunigan, D. D., and Rodriguez, R. J. 2001. Fungal symbiosis from mutualism to parasitism: Who controls the outcome, host or invader? New Phytol. 151:705-716.

Redman, R. S., Kim, Y. O., Woodward, C. J. D. A., Greer, C., Espino, L., Doty, S. L., and Rodriguez, R. J. 2011. Increased fitness of rice plants to abiotic stress via habitat adapted symbiosis: A strategy for mitigating impacts of climate change. PLoS One 6:e14823.

Redman, R. S., Ranson, J. C., and Rodriguez, R. J. 1999. Conversion of the pathogenic fungus Colletotrichum magna to a nonpathogenic endophytic mutualist by gene disruption. Mol. Plant Microbe Interact. 12:969-975.

Redman, R. S., Sheehan, K. B., Stout, R. G., Rodriguez, R. J., and Henson, J. M. 2002. Thermotolerance generated by plant/fungal symbiosis. Science 298:1581.

Rodriguez, R. J., Henson, J., Van Volkenburgh, E., Hoy, M., Wright, L., Beckwith, F., Kim, Y.-O., and Redman, R. S. 2008. Stress tolerance in plants via habitat-adapted symbiosis. ISME J. 2:404-416.

Rodriguez, R. J., Redman, R. S., and Henson, J. M. 2004. The role of fungal symbioses in the adaptation of plants to high stress environments. Mitig. Adapt. Strategies Glob. Change 9:261-272.

Rodriguez, R. J., Woodward, C., and Redman, R. S. 2010. Adaptation and survival of plants in high stress habitats via fungal endophyte conferred stress tolerance. Pages 461-476 in: Symbioses and Stress. Vol. 17. J. Seckbach and M. Grube, eds. Springer, the Netherlands.

Saunders, M., Glenn, A. E., and Kohn, L. M. 2010. Exploring the evolutionary ecology of fungal endophytes in agricultural systems: Using functional traits to reveal mechanisms in community processes. Evol. Appl. 3:525-537.

Scaduto, C. M., and Bennett, R. J. 2015. Candida albicans the chameleon: Transitions and interactions between multiple phenotypic states confer phenotypic plasticity. Curr. Opin. Microbiol. 26:102-108.

Schulz, B., and Boyle, C. 2005. The endophytic continuum. Mycol. Res. 109:661-686.

Sessitsch, A., Hardoim, P., Döring, J., Weilharter, A., Krause, A., Woyke, T., Mitter, B., Hauberg-Lotte, L., Friedrich, F., Rahalkar, M., Hurek, T., Sarkar, A., Bodrossy, L., van Overbeek, L., Brar, D., van Elsas, J. D., and ReinholdHurek, B. 2011. Functional characteristics of an endophyte community colonizing rice roots as revealed by metagenomic analysis. Mol. Plant-Microbe Interact. 25:28-36.

Sikes, B. A., Cottenie, K., and Klironomos, J. N. 2009. Plant and fungal identity determines pathogen protection of plant roots by arbuscular mycorrhizas. J. Ecol. 97:1274-1280.

Sikes, B. A., Hawkes, C. V., and Fukami, T. 2016. Plant and root endophyte assembly history: interactive effects on native and exotic plants. Ecology 97: 484-493.

Soanes, D. M., Alam, I., Cornell, M., Wong, H. M., Hedeler, C., Paton, N. W., Rattray, M., Hubbard, S. J., Oliver, S. G., and Talbot, N. J. 2008. Comparative genome analysis of filamentous fungi reveals gene family expansions associated with fungal pathogenesis. PLoS One 3:e2300.

Tack, J., Barkley, A., Rife, T. W., Poland, J. A., and Nalley, L. L. 2016. Quantifying variety-specific heat resistance and the potential for adaptation to climate change. Glob. Change Biol. 22:2904-2912.

Tan, J., Pu, Z., Ryberg, W. A., and Jiang, L. 2012. Species phylogenetic relatedness, priority effects, and ecosystem functioning. Ecology 93: 1164-1172.

Terborgh, J., Alvarez-Loayza, P., Dexter, K., Cornejo, F., and Carrasco, C. 2011. Decomposing dispersal limitation: Limits on fecundity or seed distribution? J. Ecol. 99:935-944.

Tilman, D. 1977. Resource competition between plankton algae: An experimental and theoretical approach. Ecology 58:338-348.

Tilman, D. 1999. The ecological consequences of changes in biodiversity: A search for general principles. Ecology 80:1455-1474. 
Tucker, C. M., and Fukami, T. 2014. Environmental variability counteracts priority effects to facilitate species coexistence: Evidence from nectar microbes. Proc. Biol. Sci. 281:20132637.

U'Ren, J. M., Lutzoni, F., Miadlikowska, J., Laetsch, A. D., and Arnold, A. E. 2012. Host and geographic structure of endophytic and endolichenic fungi at a continental scale. Am. J. Bot. 99:898-914.

Unterseher, M., Reiher, A., Finstermeier, K., Otto, P., and Morawetz, W. 2007. Species richness and distribution patterns of leaf-inhabiting endophytic fungi in a temperate forest canopy. Mycol. Prog. 6:201-212.

Van Veen, J. A., Overbeek, L. S., and Van Elsas, J. D. 1997. Fate and activity of microorganisms introduced into soil. Microbiol. Mol. Biol. Rev. 61:121-135.

Vanoverbeke, J., Urban, M. C., and De Meester, L. 2016. Community assembly is a race between immigration and adaptation: Eco-evolutionary interactions across spatial scales. Ecography 39:858-870.

Verbruggen, E., van der Heijden, M. G. A., Rillig, M. C., and Kiers, E. T. 2013. Mycorrhizal fungal establishment in agricultural soils: Factors determining inoculation success. New Phytol. 197:1104-1109.

Vogel, K. P., Schmer, M. R., and Mitchell, R. B. 2005. Plant adaptation regions: Ecological and climatic classification of plant materials. Rangeland Ecol. Manag. 58:315-319.

Wang, X., Zhang, X., Liu, L., Xiang, M., Wang, W., Sun, X., Che, Y., Guo, L., Liu, G., Guo, L., Wang, C., Yin, W.-B., Stadler, M., Zhang, X., and Liu, X. 2015. Genomic and transcriptomic analysis of the endophytic fungus Pestalotiopsis fici reveals its lifestyle and high potential for synthesis of natural products. BMC Genomics 16:1-13.

Warner, R. R., and Chesson, P. L. 1985. Coexistence mediated by recruitment fluctuations: A field guide to the storage effect. Am. Nat. 125:769-787.

Wearn, J. A., Sutton, B. C., Morley, N. J., and Gange, A. C. 2012. Species and organ specificity of fungal endophytes in herbaceous grassland plants. J. Ecol. 100:1085-1092.
Weinbaum, B. S., Allen, M. F., and Allen, E. B. 1996. Survival of arbuscular mycorrhizal fungi following reciprocal transplanting across the Great Basin, USA. Ecol. Appl. 6:1365-1372.

Werner, G. D. A., and Kiers, E. T. 2015. Order of arrival structures arbuscular mycorrhizal colonization of plants. New Phytol. 205:1515-1524.

West-Eberhard, M. J. 1989. Phenotypic plasticity and the origins of diversity. Annu. Rev. Ecol. Syst. 20:249-278.

Wisecaver, J. H., Slot, J. C., and Rokas, A. 2014. The evolution of fungal metabolic pathways. PLoS Genet. 10:e1004816.

Wiser, M. J., Ribeck, N., and Lenski, R. E. 2013. Long-term dynamics of adaptation in asexual populations. Science 342:1364-1367.

Worchel, E. R., Giauque, H. E., and Kivlin, S. N. 2013. Fungal symbionts alter plant drought response. Microbiol. Ecol. 65:671-678.

Zelezniak, A., Andrejev, S., Ponomarova, O., Mende, D. R., Bork, P., and Patil, K. R. 2015. Metabolic dependencies drive species co-occurrence in diverse microbial communities. Proc. Natl. Acad. Sci. 112:6449-6454.

Zhang, T., Zhang, Y.-Q., Liu, H.-Y., Wei, Y.-Z., Li, H.-L., Su, J., Zhao, L.-X., and $\mathrm{Yu}, \mathrm{L} .-\mathrm{Y} .2013$. Diversity and cold adaptation of culturable endophytic fungi from bryophytes in the Fildes Region, King George Island, maritime Antarctica. FEMS Microbiol. Lett. 341:52-61.

Zimmerman, N. B., and Vitousek, P. M. 2012. Fungal endophyte communities reflect environmental structuring across a Hawaiian landscape. Proc. Natl. Acad. Sci. 109:13022-13027.

Zomorrodi, A. R., and Maranas, C. D. 2012. OptCom: A multi-level optimization framework for the metabolic modeling and analysis of microbial communities. PLOS Comput. Biol. 8:e1002363.

Zouari, I., Salvioli, A., Chialva, M., Novero, M., Miozzi, L., Tenore, G., Bagnaresi, P., and Bonfante, P. 2014. From root to fruit: RNA-Seq analysis shows that arbuscular mycorrhizal symbiosis may affect tomato fruit metabolism. BMC Genomics 15:221. 